\title{
Retrospective Study of Postoperative Pulmonary Complications in Patients with Cervical Spine Pathology
}

\author{
Surya Kumar Dube ${ }^{1}$ Mihir Prakash Pandia ${ }^{1}$ Arvind Chaturvedi ${ }^{1}$ Shailender Kumar ${ }^{2}$ \\ ${ }^{1}$ Department of Neuroanaesthesiology and Critical Care, All India \\ Institute of Medical Sciences, New Delhi, India \\ 2Department of Anesthesiology, Pain Medicine and Critical Care, \\ All India Institute of Medical Sciences, New Delhi, India

\begin{abstract}
Address for correspondence Mihir Prakash Pandia, MD, Department Center, All India Institute of Medical Sciences, New Delhi 110029, India (e-mail: pandiamihir@gmail.com).
\end{abstract} \\ of Neuroanaesthesiology and Critical Care, 7th Floor, Neurosciences
}

J Neuroanaesthesiol Crit Care 2018;5:98-104.

\begin{abstract}
Keywords

- cervical spine

- complications

- pulmonary

- risk factors

Background Postoperative pulmonary complication (PPC) after cervical spine surgery is known to increase patient morbidity and mortality as well as the hospital and intensive care unit (ICU) stay. However, studies addressing this issue are scarce in the current literature. The aim of this study was to find out the incidence and various factors associated with PPC in patients undergoing cervical spine surgeries.

Materials and Methods It is a retrospective study in a tertiary care hospital. Two hundred and seven patients who underwent different cervical spinal surgeries were included in this study. Various perioperative data including demography, history of smoking, associated systemic illness, type and site of lesion, preoperative respiratory status, and signs of involvement of lower cranial nerves were collected. The incidence and the risk factors for PPC were found out. Statistical analysis was done using chi-square/Fisher's exact test/Student's $t$-test, followed by univariate and multiple logistic regression analysis.

Results The incidence of PPC in our study was $39.6 \%$. Various pulmonary complications observed were difficulty in breathing requiring some intervention (19.3\%), pneumonia (5.3\%), tracheobronchitis (3.9\%), arterial desaturation (3.4\%), reintubation (3.4\%), atelectasis $(1.3 \%)$, pleural effusion $(0.97 \%)$, pneumothorax $(0.97 \%)$, and acute respiratory distress syndrome (ARDS) (0.97\%). Preoperative respiratory abnormality, cervical laminectomy and instrumentation surgery and postoperative mechanical ventilation of $>24$ hours duration were found to be independent risk factors for occurrence of PPC.

Conclusions The patients with cervical spinal cord pathology are at increased risk for PPC. Preoperative respiratory abnormality, postoperative mechanical ventilation of $>$ 24-hour duration, and cervical laminectomy and instrumentation surgery are independent risk factors for PPC.
\end{abstract}

\section{Introduction}

Patients with cervical spine pathology can have respiratory system dysfunction due to weakness of respiratory muscles/ diaphragm or involvement of the respiratory center and lower cranial nerves secondary to medullary compression..$^{1,2}$ Pulmonary aspiration, atelectasis, poor respiratory function, and inadequate cough mechanism secondary to diaphragm or respiratory muscle involvement can lead to preoperative respiratory abnormalities in patients with cervical spine pathology that might get exaggerated in the postoperative period because of various anesthetic and surgical causes..$^{3-5}$ Prolonged tracheal intubation/tracheostomy in the postoperative period further can increase the incidence of pulmonary received

March 22, 2018

accepted

May 14, 2018

published online

June 10, 2018
Copyright $@ 2018$ Indian Society of Neuroanaesthesiology and Critical Care

\section{License terms \\ (이 (1) $\Theta \circledast$}


complications. ${ }^{6,7}$ However, studies addressing pulmonary complications in patients specifically with cervical spine pathology are scarce. Therefore, the objective of the study was to find out the incidence of postoperative pulmonary complication (PPC) in patient undergoing cervical spine surgeries and to identify the factors associated with PPC in these patients.

\section{Materials and Methods}

After approval of institute ethics committee, records of the patients who underwent surgery for different cervical spinal cord/vertebral pathology within a stipulated 2-year-duration were reviewed. Patients who underwent surgery for craniovertebral junction (CVJ) anomaly were excluded from the study.

Demographic data and data regarding associated systemic illness, type and site of pathology, preoperative respiratory status, and signs of involvement of lower cranial nerves were collected. If there were documented positive signs or symptoms of respiratory abnormality, need for airway or respiratory support, abnormal sounds on chest auscultation, or presence of abnormal chest X-ray, the patient was considered to have preoperative respiratory system abnormality. Data about anesthetic technique, intubation techniques, surgical procedure, levels of the cervical vertebra operated, duration of surgery and anesthesia, amount of blood loss, amount of intravenous fluid used, amount of blood, and blood component transfused were noted.

Postoperative data were reviewed for the presence of PPC, need for reintubation/other airway intervention, need and duration of postoperative mechanical ventilation, blood and blood component transfusion, other complications, need for reexploration, postoperative use of methyl prednisolone, nasogastric tube (NGT) insertion, and duration of intensive care unit (ICU) and hospital stay.

Presence of any one or more of the following was considered as PPC: hypoventilation, hyperventilation, presence of abnormal signs or symptoms of pulmonary system, difficulty in breathing requiring intervention (i.e., intubation, airway insertion, nebulization, maneuvers to keep airway patent, etc.) arterial oxygen saturation $<90 \%$ needing oxygen supplementation, atelectasis, pneumothorax, pleural effusion, hemothorax, abnormal chest auscultatory findings, pneumonia, tracheobronchitis, or acute respiratory distress syndrome (ARDS).

The statistical analysis was performed using Stata 11.0 (College Stations, Texas, United States). Data were presented as number (\%)/mean \pm standard deviation (SD)/median (range). Demographic and clinical characteristics of the patients were compared using chi-square/Fisher's exact test (for categorical variables) and Student's $t$-test (for continuous variables). The risk factors for PPC were found out using univariate analysis followed by multiple logistic regression analysis. The results were shown as odds ratio (OR) ( $95 \%$ confidence interval $[\mathrm{CI}]$ ). $p$-Value $<0.05$ was considered as significant.

\section{Results}

Data of 207 patients (160 [80.7\%] males) were analyzed in this study. Different demographic characteristics of the patients are shown in - Table 1. The median age of the patients was 49 years ( 3 months-86 years), and most of the patients were of ASA (American Society of Anesthesiologists) class I (54.1\%) and II (44.9\%). Perioperative characteristics of the patients are shown in - Table 2. Forty-four (21.3\%) patients were smokers and 34 (16.4\%) had preoperative respiratory abnormality. Majority of the patients had prolapsed intervertebral disc (39.7\%), and $28.5 \%$ of patients had involvement of multiple cervical levels. Majority of our patients underwent anterior cervical discectomy and fusion (ACDF) (39.7\%) and cervical laminoplasty (39.1\%) surgery. The surgical approach was anterior in $50.7 \%$ patients and posterior in $48.3 \%$ patients. The mean durations of surgery and anesthesia were $201.2 \pm 91$ minutes and $260.4 \pm 98.1$ minutes, respectively. Forty-five (27.8\%) patients required mechanical ventilation in the postoperative period, and the mean duration of mechanical ventilation was $13.1 \pm 60.7$ hours. Five (2.4\%) patients required tracheostomy. Methyl prednisolone was

Table 1 Demographic characteristics of the patients $(n=207)^{\mathrm{a}}$

\begin{tabular}{|l|l|}
\hline Parameter & Frequency \\
\hline Age $(\mathrm{y})^{\mathrm{b}}$ & $49(3 \mathrm{mo}-86 \mathrm{y})$ \\
\hline Weight $(\mathrm{kg})^{\mathrm{b}}$ & $60(5-105)$ \\
\hline ASA status & $112(54.1)$ \\
\hline I & $93(44.9)$ \\
\hline II & $2(1.0)$ \\
\hline III & 0 \\
\hline IV & \\
\hline Sex & $160(80.7)$ \\
\hline Male & $47(19.3)$ \\
\hline Female & \\
\hline
\end{tabular}

Abbreviation: ASA, American Society of Anesthesiologists.

aData shown as number (\%) of patients unless specified.

bata shown as median (range). 
Table 2 Perioperative characteristics of the patients $(n=207)^{\mathrm{a}}$

\begin{tabular}{|c|c|}
\hline Parameter & Frequency \\
\hline Smokers & $44(21.3)$ \\
\hline Preoperative respiratory system abnormality & $34(16.4)$ \\
\hline \multicolumn{2}{|l|}{ Diagnosis } \\
\hline PIVD & $82(39.7)$ \\
\hline SOL & $31(14.8)$ \\
\hline Myelopathy & $37(17.9)$ \\
\hline others & $57(27.6)$ \\
\hline \multicolumn{2}{|l|}{ Level of injury } \\
\hline Upper & $13(6.3)$ \\
\hline Middle & $46(22.2)$ \\
\hline Lower & $89(43)$ \\
\hline Multiple & $59(28.5)$ \\
\hline \multicolumn{2}{|l|}{ Surgery performed } \\
\hline ACDF & $82(39.7)$ \\
\hline Laminoplasty & $81(39.1)$ \\
\hline Laminectomy and instrumentation & $44(21.2)$ \\
\hline \multicolumn{2}{|l|}{ Approach } \\
\hline Anterior & $105(50.7)$ \\
\hline Posterior & $100(48.3)$ \\
\hline Combined & $2(1)$ \\
\hline Duration of surgery (minutes) $)^{b}$ & $201.2 \pm 91$ \\
\hline Duration of anesthesia (minutes) ${ }^{\mathrm{b}}$ & $260.4 \pm 98.1$ \\
\hline Blood loss $(\mathrm{mL})^{\mathrm{b}}$ & $342.9 \pm 367.4$ \\
\hline Fluid $(\mathrm{mL})^{\mathrm{b}}$ & $2473 \pm 964.7$ \\
\hline Mechanical ventilation & $45(27.8)$ \\
\hline Duration of mechanical ventilation $(h)^{b}$ & $13.1 \pm 60.7$ \\
\hline Need for tracheostomy & $5(2.4)$ \\
\hline Methyl prednisolone administration & $24(11.6)$ \\
\hline ICU stay $(\mathrm{h})^{\mathrm{b}}$ & $36.6 \pm 52.3$ \\
\hline Hospital stay $(\mathrm{d})^{\mathrm{b}}$ & $5.5 \pm 5.1$ \\
\hline
\end{tabular}

Abbreviations: ACDF: anterior cervical discectomy and fusion; ASA: American Society of Anesthesiologists; ICU, intensive care unit; PIVD: prolapsed intervertebral disc; SOL, space-occupying lesion.

aData shown as number (\%) of patients unless specified.

${ }^{b}$ Data shown as mean $( \pm S D)$.

administered in 24 (11.6\%) patients. The mean ICU stay (ICS) was $36.6 \pm 52.3$ hours, whereas the mean hospital stay (HOS) was $5.5 \pm 5.1$ days.

In the postoperative period, $82(39.6 \%)$ patients developed various pulmonary complications (-Table 3 ). The most common pulmonary complication was difficulty in breathing requiring some intervention (19.3\%). Based on the presence or absence of PPC, patients were divided into two groups: group P (presence of PPC) and group A (absence of PPC). Comparison of different demographic and perioperative variables is shown in - Table 4. Patients of both the groups were comparable in terms of age, sex distribution, weight, ASA status, and level of pathology. Group P had significantly more number of smokers, more patients with preoperative respiratory abnormality, longer duration of surgery and anesthesia, amount of blood loss intravenous fluid administration, and duration of postoperative mechanical ventilation than group A. Incidence of tracheostomy and methyl prednisolone administration was more in group $P$ than group $A$. The ICU stay and hospital stay were longer in group $\mathrm{P}$ than group $\mathrm{A}$.

The results of univariate analysis are shown in - Table $\mathbf{5}$. In univariate analysis, age > 60 years, smoking, preoperative respiratory abnormality, posterior approach surgery, cervical laminoplasty and cervical laminectomy and instrumentation surgery, duration of anesthesia > 300 minutes, intraoperative blood loss $>500 \mathrm{~mL}$, intravenous fluid administration of $>2,000 \mathrm{ml}$, administration of methyl prednisolone, postoperative mechanical ventilation $>24$ hours, and neoplastic space-occupying lesions were statistically significant risk factors for PPC. 
Table 3 Incidence of different postoperative pulmonary complications ( $n=207)^{\text {a }}$

\begin{tabular}{|l|l|}
\hline Pulmonary complication & Frequency \\
\hline Difficulty in breathing requiring intervention & $40(19.3)$ \\
\hline Pneumonia & $11(5.3)$ \\
\hline Tracheobronchitis & $8(3.9)$ \\
\hline Desaturation $\left(\mathrm{SpO}_{2}<90 \%\right)$ & $7(3.4)$ \\
\hline Reintubation & $7(3.4)$ \\
\hline Atelectasis & $3(1.3)$ \\
\hline Pleural effusion & $2(0.97)$ \\
\hline Pneumothorax & $2(0.97)$ \\
\hline ARDS & $2(0.97)$ \\
\hline
\end{tabular}

Abbreviation: ARDS, acute respiratory distress syndrome.

aData shown as number (\%) of patients.

The results of multivariate analysis are shown in - Table 6. In multivariate analysis, only preoperative respiratory abnormality, cervical laminectomy and instrumentation surgery, and postoperative mechanical ventilation of $>24$ hours were found to be independent risk factors for PPC.

\section{Discussion}

We conducted this retrospective study to find out the incidences and nature of various pulmonary complications and the associated risk factors in patients who underwent cervical spine surgery. The incidence of PPC in our study was $39.6 \%$. The most common pulmonary complication was difficulty in breathing requiring some intervention (19.3\%). The reported incidence of PPC after various procedures varies between 2.5 and $37 \%{ }^{8-15}$ This large variation in the incidence of PPCs can be ascribed to differences in different definitions used for pulmonary complications, preoperative patient's conditions, types of surgery, and duration of postoperative follow-up. Our definition of PPC was more inclusive because, in addition to specific pulmonary pathologies, such as pneumonia, atelectasis, and ARDS, it included nonspecific pulmonary conditions such as respiratory distress or hypoxemia that always cannot be attributed to any specific pulmonary pathology and can lead to life-threatening situations and needs urgent intervention. We found a higher incidence of PPCs because of the inclusion of nonspecific pulmonary conditions such as difficulty in breathing requiring intervention.

Preoperative respiratory system abnormality was present in $34(16.4 \%)$ patients in our study, and we found it to be an independent risk factor for PPC (OR, 6.8; 95\% CI $[2.9,15.9] ; p<0.0001)$. Studies have demonstrated preoperative respiratory abnormality to be associated with increased risk of pulmonary complication. ${ }^{16,17}$ Chronic obstructive pulmonary disease (COPD) is one of the most important risk factors for PPC. Patients with severe COPD are more likely to have a PPC, and COPD was found to be an independent predictor of increased mortality in patients undergoing cardiac surgeries. ${ }^{18}$

Laminectomy and instrumentation surgery was also an independent risk factor for PPC in our study. This could also be explained on the basis of posterior surgical approach used in these surgeries. Tani et al compared the relative safety of anterior corpectomy (anterior approach surgery) versus laminoplasty (posterior approach) surgery. As compared with laminoplasty, patients treated with a corpectomy were noted to have significantly better functional results and no postoperative neurological complications. Patients treated with a laminoplasty were noted to have significant neurological deterioration. ${ }^{19}$ In addition, posterior approach for cervical pathologies is reported to be associated with increased risk for infection, increased postoperative neck pain, and postlaminectomy kyphosis. ${ }^{20}$ Postoperative pain may impair patient's ability to cough in the postoperative period, leading to retention of pulmonary secretion causing pulmonary infection. Hence this might have contributed toward an increased incidence of PPC in patients who underwent laminectomy and instrumentation surgery

Duration of postoperative mechanical ventilation of $>24$ hours was another independent risk factor for PPC in our study (OR, 43.2; 95\% CI [5.5, 337.1]; $p<0.0001$ ). Tracheal tubes are known conduits for lower airway contamination and can lead to chest infection. Greater duration of postoperative mechanical ventilation might have predisposed patients to PPC, leading to higher incidence of PPC in those patients. Volutrauma and barotraumas associated with mechanical ventilation is thought to generate physical damage as well as pulmonary inflammatory response leading to pulmonary dysfunction. ${ }^{21}$ Postoperative mechanical ventilation is known to increase the chance of PPC in patients after spine surgery. ${ }^{22}$ In our study, patients with PPCs had significantly longer ICU stay than those who did not have PPCs ( - Table 4). In patients with cervical spinal cord injury, length of hospital stay and hospital costs were reported to increase with the number of respiratory complications experienced during the hospitalization. ${ }^{23}$

The major limitation of our study is that it is a retrospective study. We may have missed many cases because of inadequate data recording. We had no data about the preand postoperative pulmonary function tests of the patients, which could have added to our understanding of PPCs. Many of these limitations can be minimized with a prospective 
Table 4 Comparison of different variables in patients with and without PPC $(n=207)^{\text {a }}$

\begin{tabular}{|c|c|c|c|}
\hline Parameter & Group $P(n=82)$ & Group A $(n=125)$ & $p$-Value \\
\hline Age $(y)^{b}$ & $47.5 \pm 19.4$ & $44.76 \pm 16.7$ & 0.28 \\
\hline \multicolumn{4}{|l|}{ Sex } \\
\hline Male & $66(80.4)$ & $101(80.8)$ & \multirow{2}{*}{0.95} \\
\hline Female & $16(19.6)$ & $24(19.2)$ & \\
\hline Weight $(\mathrm{kg})^{\mathrm{b}}$ & $58.9 \pm 17.3$ & $60.2 \pm 17$ & 0.63 \\
\hline \multicolumn{4}{|l|}{ ASA status } \\
\hline 1 & $38(46.3)$ & $74(59.2)$ & \multirow{4}{*}{0.06} \\
\hline II & $42(51.2)$ & $51(40.8)$ & \\
\hline III & $2(2.5)$ & 0 & \\
\hline IV & 0 & 0 & \\
\hline Smoking & $24(29.2)$ & $20(16)$ & 0.02 \\
\hline Respiratory abnormality & $26(31.7)$ & $8(6.4)$ & 0.001 \\
\hline \multicolumn{4}{|l|}{ Diagnosis } \\
\hline PIVD & $23(28)$ & $59(47.2)$ & \multirow{4}{*}{0.005} \\
\hline SOL & $18(21.9)$ & $13(10.4)$ & \\
\hline Myelopathy & $12(14.6)$ & $25(20)$ & \\
\hline others & $29(35.5)$ & $28(22.4)$ & \\
\hline \multicolumn{4}{|l|}{ Level } \\
\hline Upper & $8(9.8)$ & $5(4)$ & \multirow{4}{*}{0.21} \\
\hline Middle & $18(22)$ & $28(22.4)$ & \\
\hline Lower & $30(36.6)$ & $59(47.2)$ & \\
\hline Multiple & $26(31.7)$ & $33(26.4)$ & \\
\hline \multicolumn{4}{|l|}{ Approach } \\
\hline Anterior & $32(39)$ & $73(58.4)$ & \multirow{3}{*}{0.008} \\
\hline Posterior & $48(58.5)$ & $52(41.6)$ & \\
\hline Combined & $2(2.5)$ & 0 & \\
\hline \multicolumn{4}{|l|}{ Surgery } \\
\hline ACDF & $18(21.9)$ & $63(50.4)$ & \multirow{3}{*}{$<0.001$} \\
\hline Laminoplasty & $38(46.3)$ & $43(34.4)$ & \\
\hline Laminectomy and instrumentation & $26(31.7)$ & $19(15.2)$ & \\
\hline Duration of surgery (min) ${ }^{b}$ & $236.8 \pm 109.3$ & $177.8 \pm 67.6$ & 0.004 \\
\hline Duration of anesthesia $(\min )^{b}$ & $298.1 \pm 120.3$ & $235.7 \pm 70.6$ & $<0.001$ \\
\hline Blood loss $(\mathrm{mL})^{\mathrm{b}}$ & $462.6 \pm 448.6$ & $264.5 \pm 277.7$ & $<0.001$ \\
\hline Fluid $(\mathrm{mL})^{\mathrm{b}}$ & $2804.4 \pm 1143$ & $2255 \pm 756.7$ & 0.004 \\
\hline \multicolumn{4}{|l|}{ Tracheostomy } \\
\hline Yes & $5(6.1)$ & 0 & \multirow{2}{*}{0.005} \\
\hline No & 77 (93.9) & $125(100)$ & \\
\hline \multicolumn{4}{|l|}{ Methyl prednisolone use } \\
\hline Yes & $15(18.5)$ & $9(7.2)$ & \multirow{2}{*}{0.013} \\
\hline No & $67(81.5)$ & $116(92.3)$ & \\
\hline Mechanical ventilation $(h)^{b}$ & $32 \pm 93.6$ & $0.7 \pm 3.64$ & $<0.001$ \\
\hline ICU stay $(h)^{b}$ & $62.5 \pm 75.7$ & $19.5 \pm 8.3$ & $<0.001$ \\
\hline Hospital stay $(\mathrm{d})^{\mathrm{b}}$ & $7.6 \pm 6.9$ & $4 \pm 2.6$ & $<0.001$ \\
\hline
\end{tabular}

Abbreviations: ACDF, anterior cervical discectomy and fusion; ASA, American Society of Anesthesiologists; ICU, intensive care unit; PIVD, prolapsed intervertebral disc; PPC, postoperative pulmonary complication; SOL, space-occupying lesions.

aData shown as number (\%) of patients unless specified.

${ }^{\mathrm{b}}$ Data shown as mean $( \pm \mathrm{SD})$. 
Table 5 Univariate analysis of relative risk for PPC $(n=207)^{\text {a }}$

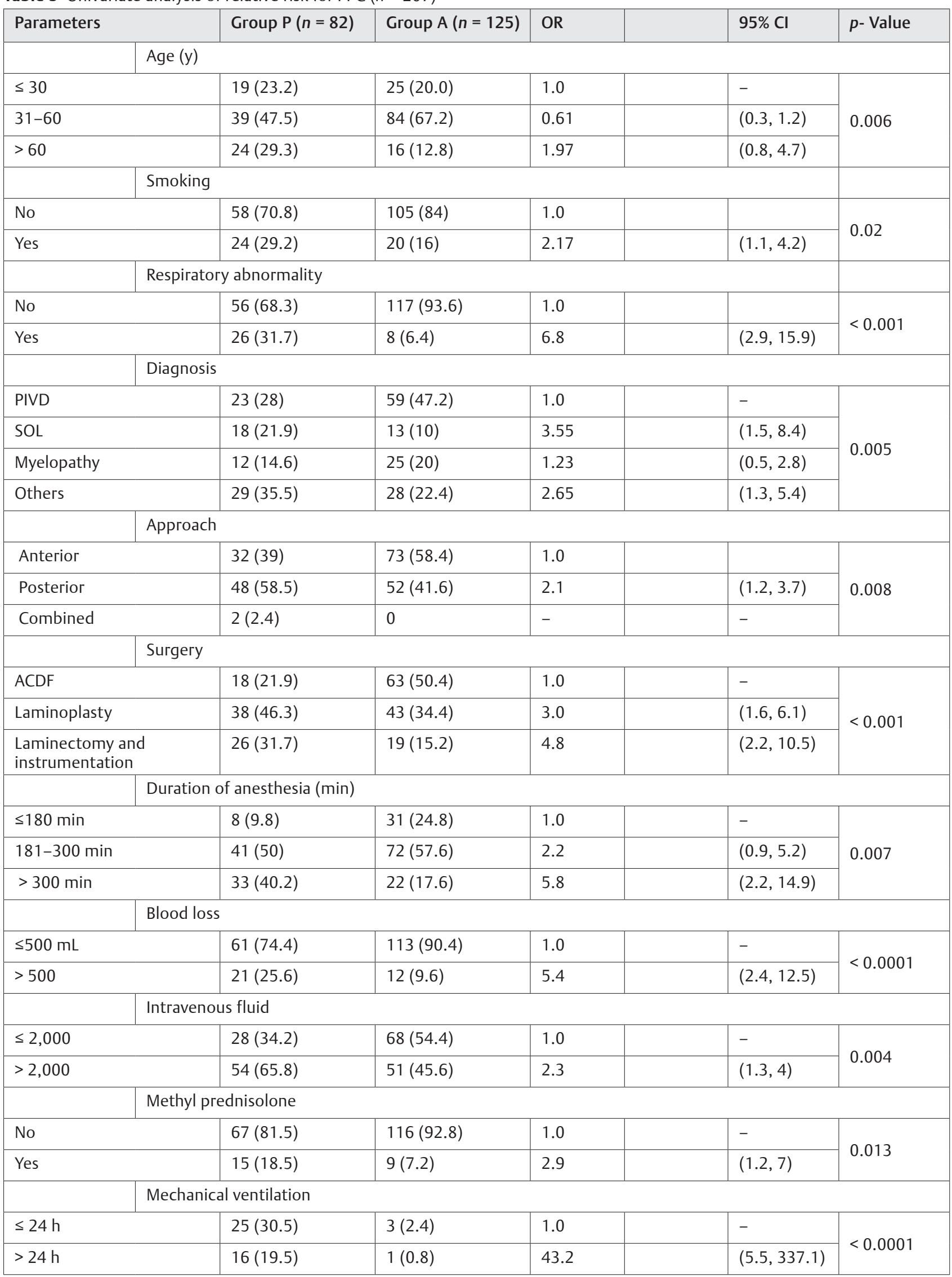

Abbreviations: ACDF, anterior cervical discectomy and fusion; CI, confidence interval; OR, odds ratio; PIVD, prolapsed intervertebral disc; PPC, postoperative pulmonary complication; SOL, space-occupying lesions.

aData shown as number (\%). 
Table 6 Multivariate analysis of PPC

\begin{tabular}{|l|l|l|}
\hline Parameters & OR & $95 \% \mathrm{CI}$ \\
\hline Respiratory abnormality & 5.4 & $(1.8,16.6)$ \\
\hline Laminectomy and instrumentation & 8.35 & $(1.9,37.3)$ \\
\hline Mechanical ventilation (> 24 h) & 51.3 & $(5.4,489)$ \\
\hline
\end{tabular}

Abbreviations: $\mathrm{Cl}$, confidence interval; OR, odds ratio; PPC, postoperative pulmonary complication.

study. Despite these limitations, our study showed that PPCs are common in patients with cervical spine pathologies, which can prolong the duration of ICU and hospital stay.

\section{Conclusion}

Patients with cervical spinal cord pathology are at increased risk for PPCs. There is a strong association between PPCs and preoperative respiratory abnormality, postoperative mechanical ventilation > 24 hours, and cervical laminectomy and instrumentation surgery. Patients with PPC had significantly longer ICU and hospital stay. Future large prospective studies can substantiate our findings and provide more useful information on PPCs in patients with cervical spine pathologies.

\section{Funding \\ None.}

\section{Conflict of Interest}

None.

\section{References}

1 Lahuerta J, Buxton P, Lipton S, Bowsher D. The location and function of respiratory fibres in the second cervical spinal cord segment: respiratory dysfunction syndrome after cervical cordotomy.J Neurol Neurosurg Psychiatry 1992;55(12):1142-1145

2 Rosomoff HL. Occult respiratory and autonomic dysfunction in craniovertebral anomalies and upper cervical spinal disease. Spine 1986;11(4):345-347

3 Toyoda H, Nakamura H, Konishi S, Terai H, Takaoka K. Does chronic cervical myelopathy affect respiratory function? J Neurosurg Spine 2004;1(2):175-178

4 Wadia NH. Myelopathy complicating congenital atlanto-axial dislocation. (A study of 28 cases. Brain 1967;90(2):449-472

5 Smith PH, Benn RT, Sharp J. Natural history of rheumatoid cervical luxations. Ann Rheum Dis 1972;31(6):431-439

6 Taggard DA, Traynelis VC. Management of cervical spinal fractures in ankylosing spondylitis with posterior fixation. Spine 2000;25(16):2035-2039

7 Sawin PD, Traynelis VC. Posterior articular mass plate fixation of the sub-axial cervical spine. In: Menezes AH, Sonntag VKH, eds. Principles of Spinal Surgery. New York, NY: McGraw-Hill; 1996:1081-1104

8 Mitchell CK, Smoger SH, Pfeifer MP, et al. Multivariate analysis of factors associated with postoperative pulmonary complications following general elective surgery. Arch Surg 1998;133(2):194-198

9 McAlister FA, Bertsch K, Man J, Bradley J, Jacka M. Incidence of and risk factors for pulmonary complications after nonthoracic surgery. Am J Respir Crit Care Med 2005;171(5):514-517

10 Hall JC, Tarala RA, Hall JL, Mander J. A multivariate analysis of the risk of pulmonary complications after laparotomy. Chest 1991;99(4):923-927

11 Brooks-Brunn JA. Predictors of postoperative pulmonary complications following abdominal surgery. Chest 1997;111(3):564-571

12 Avendano CE, Flume PA, Silvestri GA, King LB, Reed CE. Pulmonary complications after esophagectomy. Ann Thorac Surg 2002;73(3):922-926

13 Fuso L, Cisternino L, Di Napoli A, et al. Role of spirometric and arterial gas data in predicting pulmonary complications after abdominal surgery. Respir Med 2000;94(12):1171-1176

14 Hoyt DB, Simons RK, Winchell RJ, et al. A risk analysis of pulmonary complications following major trauma. J Trauma 1993;35(4):524-531

15 Roukema JA, Carol EJ, Prins JG. The prevention of pulmonary complications after upper abdominal surgery in patients with noncompromised pulmonary status. Arch Surg 1988;123(1):30-34

16 Lawrence VA, Dhanda R, Hilsenbeck SG, Page CP. Risk of pulmonary complications after elective abdominal surgery. Chest 1996;110(3):744-750

17 McAlister FA, Khan NA, Straus SE, et al. Accuracy of the preoperative assessment in predicting pulmonary risk after nonthoracic surgery. Am J Respir Crit Care Med 2003; 167(5):741-744

18 Fuster RG, Argudo JA, Albarova OG, et al. Prognostic value of chronic obstructive pulmonary disease in coronary artery bypass grafting. Eur J Cardiothorac Surg 2006;29(2):202-209

19 Tani T, Ushida T, Ishida K, Iai H, Noguchi T, Yamamoto H. Relative safety of anterior microsurgical decompression versus laminoplasty for cervical myelopathy with a massive ossified posterior longitudinal ligament. Spine 2002;27(22):2491-2498

20 Herkowitz HN. A comparison of anterior cervical fusion, cervical laminectomy, and cervical laminoplasty for the surgical management of multiple level spondylotic radiculopathy. Spine 1988;13(7):774-780

21 Dreyfuss D, Saumon G. Ventilator-induced lung injury: lessons from experimental studies. Am J Respir Crit Care Med 1998;157(1):294-323

22 Stundner O, Taher F, Pawar A, Memtsoudis SG. Pulmonary complications after spine surgery. World J Orthop 2012;3(10):156-161

23 Winslow C, Bode RK, Dan Felton D, Chen D, Meyer PR Jr. Impact of respiratory complications on length of stay and hospital costs in acute cervical spine injury. Chest 2002;121 (5):1548-1554 